\title{
Solid Variant of Alveolar Rhabdomyosarcoma of Nasal Cavity
} Bhattarai A, Shrestha BL, Dhakal A

Department of Otorhinolaryngology-Head and Neck Surgery,

Kathmandu University School of Medical Sciences,

Dhulikhel, Kavre, Nepal.

\section{Corresponding Author}

Anuja Bhattarai

Department of Otorhinolaryngology-Head and Neck Surgery,

Kathmandu University School of Medical Sciences,

Dhulikhel, Kavre, Nepal.

E-mail: avang.dbj@gmail.com

Citation

Bhattarai A, Shrestha BL, Dhakal A. Solid Variant of Alveolar Rhabdomyosarcoma of Nasal Cavity. Kathmandu Univ Med J. 2020;69(1):102-4.

\begin{abstract}
Rhabdomyosarcoma comprises about half of the soft tissue tumors. Approximately $40 \%$ of the alveolar subtype occur in the head and neck region. Patients present with unilateral nasal mass with/without lymphadenopathy and with/without orbital manifestations. Diagnosis is aided radiologically by CT scan, MRI along with biopsy and is confirmed by immunohistochemistry. Treatment involves surgical resection, chemotherapy, radiotherapy or a combination of these. In spite of treatments, however, the outcome is poor. This is a case report of 14-year-old male who presented with unilateral nasal mass with proptosis of right eye who was eventually diagnosed as a case of alveolar rhabdomyosarcoma of solid variant.
\end{abstract}

\section{KEY WORDS}

Alveolar rhabdomyosarcoma, Immunohistochemistry, Nasal cavity

\section{INTRODUCTION}

Sarcoma are rare entity among the mesenchymal malignant neoplasms. ${ }^{1}$ Rhabdomyosarcoma, however, is considered most common of the soft tissue sarcoma comprising approximately about $50 \%$ of the tumors. $4-8 \%$ of these malignant lesions occur in patients younger than 15 years. ${ }^{2}$

Among the subtypes of rhabdomyosarcoma, alveolar subtype is rare. This subtype involves head and neck region in $40 \%$, genitourinary system in $20 \%$, extremities in $20 \%$, trunk in $10 \%$ and other sites in $10 \% .^{3}$ Children are more affected than adults. Also, it has a poor outcome due to its higher propensity to metastasize. ${ }^{4}$ Local invasion to temporal bone and distant metastasis to meninges, bone, lungs have been described. ${ }^{5}$ Hence, timely diagnosis and appropriate interventions are absolutely necessary for a better outcome.

\section{CASE REPORT}

A 14-year-old male patient presented to our ENT- Out Patient Department with complain of right sided nasal bleeding and nasal obstruction for one and half months. There was also history of protruding of right eyeball with double vision after biopsy was conducted in a nearby health center 1 month back. Contrast enhanced CT scan of nose and paranasal sinuses (PNS) showed a $3.2 \times 2.7 \times 5.4 \mathrm{~cm}$ lesion in right nasal cavity with erosion of all the turbinates, right nasolacrimal duct and medial and inferior wall of right orbit with extension in intraconal compartment. Superiorly, lesion extended into ethmoidal and frontal sinuses. MRI with contrast revealed maxillary soft tissue infiltration with breech of medial and lateral wall of maxillary sinus. (fig. 1) However, no intracranial extension was noted. After discussion with ophthalmology and Oral Maxillofacial Surgery (OMFS) departments, excision of nasal mass with subtotal maxillectomy and debulking of right eye tumor 


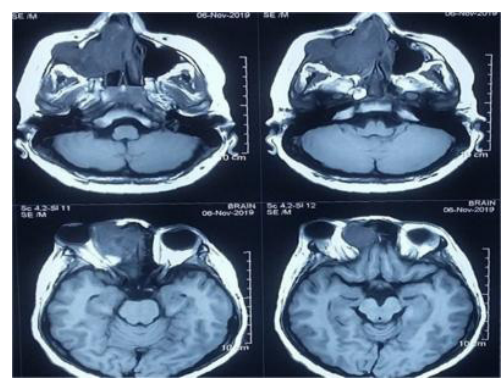

Figure 1. T1 weighted MRI scan showing tumor and its extension

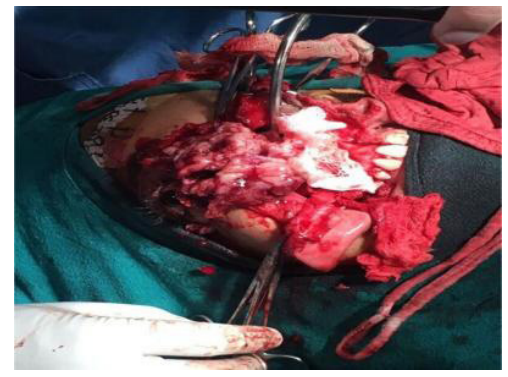

Figure 2. Tumor seen during surgery

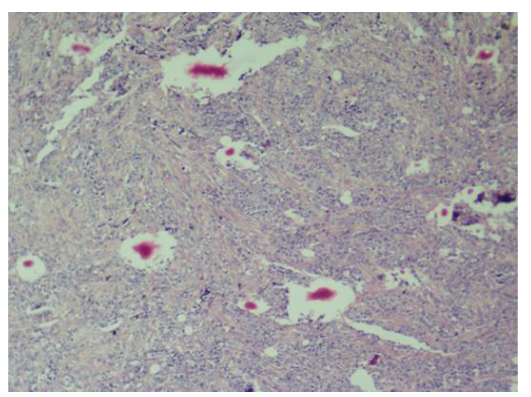

Figure 3. Small round blue cell tumor as seen in histopathology

mass was done (fig. 2). HPE report revealed small round cell tumor (fig. 3). In immunohistochemistry, the tumor cells stained diffuse strong positive for Myogenin, diffuse moderate to strong positive for MyoD1 and focal strong positive for Desmin. Thus, a diagnosis of solid variant of Alveolar rhabdomyosarcoma was made. The patient was then referred to oncology center for further chemoradiation due to unavailability at our center.

\section{DISCUSSION}

Rhabdomyosarcoma is a malignant tumor arising from striated skeletal muscles. It was first described in English literature in 1937 and in 1992 in children as a tumor mainly composed of bundles of cells with myogenic differentiation by immunohistochemical and ultrastructural analysis. Subtypes of this tumor are classified according to their histology into: Embryonic (further classified into embryonic, botryoid and spindle cell tumors), alveolar or pleomorphic. Alveolar subtype is the second commonest subtype in children after embryonic. ${ }^{6}$ Within the head and neck, according to the sites involved, rhabdomyosarcoma can further be classified as: Orbital, nonorbital parameningeal (including the sinonasal region), and nonorbital nonparameningeal.
Relating alveolar rhabdomyosarcoma with genetics, there is reproducible tumor specific chromosomal translocation, $\mathrm{t}(2 ; 13)$ (q35; q14), resulting in PAX3-FOXO1 fusion. ${ }^{7}$

There is wide variation in age in relation to incidence with earliest reported diagnosis at birth and most advanced age of 61 years. Children are seen to be most frequently involved whereas there is rare occurrence in adults., ${ }^{5,8}$

Patients often present with a history of short duration with high stage disease. ${ }^{9}$ The common symptoms are nasal block, rhinorrhea, nasal bleeding, snoring, cheek swelling, painful swallowing, facial paralysis, orbital pain and loss of weight. ${ }^{10}$ There is also history of unilateral sinus symptoms found to be initially, misdiagnosed several times, as acute sinusitis, reported in the literature. ${ }^{11}$ On examination, fleshy, irregular mass is seen. ${ }^{8}$ Upper jaw or maxillary swelling are appreciated only in some cases. There may be progressive bulging and inflammation of orbit in case of orbital involvement with decrease of visual acuity, severe proptosis, inferior and lateral displacement of eyeball, complete ophthalmoplegia, optic nerve avulsion.10 Lymph nodes may or may not be involved. In case of involvement, preauricular, submandibular, latero-

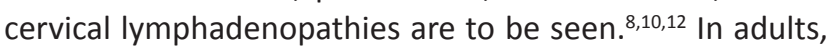
the uncommon manifestations reported in literature are metastatic disease in the temporal bone, meninges, lungs, mediastinum, bones, pancreas, right ovary and orbital apex syndrome. . $, 8,11,13$

CECT and MRI aids in radiological diagnosis. CT imaging is done to evaluate the primary tumor and define the surrounding vital structures as well as to look for any bone erosion. It has been reported that tumors more than $5 \mathrm{~cm}$ in diameter have a poorer prognosis. ${ }^{14} \mathrm{MRI}$ focuses on the soft tissue extension.

Microscopically, solid sheets of small, round cells with scant cytoplasm and hyperchromatic nuclei is seen. Alveolar type characteristically shows small round rhabdomyoblasts arranged in nests or cards separated by connective tissue trabeculae with focal areas of alveolar architecture. Hence, it resembles the alveoli of lungs. Also, tumors from mucosal surfaces are mostly seen to be of the alveolar subtype.

Solid forms of alveolar rhabdomyosarcoma lack the prominent nested pattern and cellular discohesion seen in classical type. These closely mimic other round cell tumors like small cell carcinoma, lymphoma, neuroblastoma and malignant melanoma. ${ }^{15}$ Diagnosis is, then, confirmed by immunohistochemistry. Alveolar rhabdomyosarcoma are seen to stain strong positive for desmin, myogenin, MSA, vimentin and MYOD1 in immunohistochemistry. ${ }^{9,13}$

Treatment is by surgical excision, radiotherapy, chemotherapy or a combination of these. Adequate resection is said to have achieved by resecting $0.5 \mathrm{~cm}$ of normal tissue around the tumor mass. ${ }^{5,14}$ Vincristine, actinomycin D, cyclophosphamide and adriamycin are the most commonly used agents for chemotherapy till date. ${ }^{16}$ 
If there is recurrence following initial therapy, patients are advised for radiotherapy. ${ }^{5}$

Prognosis is poor in adults compared to children. ${ }^{17}$ Factors associated with poor outcome are adult onset of disease, alveolar histology and treatment with systemic chemotherapy for less than 1 year. ${ }^{3}$

\section{REFERENCES}

1. Maurer HM, Crist W, Lawrence W, Ragab AH, Raney RB, Webber B, et al. The intergroup rhabdomyosarcoma study-I. A final report. Cancer. 1988 Jan 15;61(2):209-20.

2. Ries LA, Smith MA, Gurney JG, Linet M, Tamra T, Young JL, et al. Cancer incidence and survival among children and adolescents: United States SEER Program 1975-1995. Cancer incidence and survival among children and adolescents: United States SEER Program. 1975-1995. 1999.

3. Callender $\mathrm{T}$, Weber $\mathrm{R}$, Janjan $\mathrm{N}$, Benjamin $\mathrm{R}$, Zaher $\mathrm{M}$, Wolf $\mathrm{P}$, et al. Rhabdomyosarcoma of the nose and paranasal sinuses in adults and children. Otolaryngol Head Neck Surg. 1995 Feb;112(2):252-7.

4. Meza JL, Anderson J, Pappo AS, Meyer WH. Analysis of Prognostic Factors in Patients With Nonmetastatic Rhabdomyosarcoma Treated on Intergroup Rhabdomyosarcoma Studies III and IV: The Children's Oncology Group. J Clin Oncol. 2006 Aug 20;24(24):3844-51.

5. Moretti G, Guimarães R, de Oliveira KM, Sanjar F, Louis R. Rhabdomyosarcoma of the head and neck: 24 cases and literature review. Braz J Otorhinolaryngol. 2010;5.

6. Ahmed AA, Tsokos M. Sinonasal Rhabdomyosarcoma in Children and Young Adults. Int J Surg Pathol. 2007 Apr;15(2):160-5.

7. Tilley C, Christopher DM. Fletcher Diagnostic Histopathology of Tumors, $4^{\text {th }}$ ed. Elsevier Saunders, Philadelphia, 2013. 2296 Pages. ISBN-10: 1437715346; ISBN-13: 978-1437715347.: Book review. Neuropathol Appl Neurobiol. 2015 Oct;41(6):853-3.

8. Rajinder S, Rohaizam J, Irfan M. Alveolar-type rhabdomyosarcoma of nasal cavity and paranasal sinus in adult with pulmonary metastasis: A case report. Egypt J Ear Nose Throat Allied Sci. 2016 Nov; 17(3): 177-9.
Among the subtypes of rhabdomyosarcoma, alveolar rhabdomyosarcoma is most commonly seen in children. The rare manifestations of orbital apex syndrome and pulmonary metastasis have only been described in adults. Children usually have a good prognosis. Hence, timely diagnosis and appropriate investigations are absolutely necessary for early initiation of treatment and a better outcome.

9. Thompson LDR, Jo VY, Agaimy A, Llombart-Bosch A, Morales GN, Machado I, et al. Sinonasal Tract Alveolar Rhabdomyosarcoma in Adults: A Clinicopathologic and Immunophenotypic Study of FiftyTwo Cases with Emphasis on Epithelial Immunoreactivity. Head Neck Pathol. 2018 Jun;12(2):181-92.

10. Torres-Peña JL, Castrillo Al, Mencía-Gutiérrez E, Gutiérrez-Díaz E, Rodríguez-Peralto JL, Bengoa-González Á. Nasal cavity or alveolar paranasal sinus rhabdomyosarcoma with orbital extension in adults: 2 cases. Plastic and Reconstructive Surgery Global Open. 2015 Jun;3(6).

11. Dilger A, Schneider A, Cramer J, Shintani Smith S. Rhabdomyosarcoma of the Paranasal Sinuses Initially Diagnosed as Acute Sinusitis. Sinusitis. 2017 Feb 4;2(1):2.

12. Nayak DR, Balakrishnan R, Shahab AS, Rao L. Alveolar rhabdomyosarcoma of paranasal sinus with cervical metastasis-a case report. Indian Journal of Otolaryngology and Head and Neck Surgery. 2000 Apr 1;52(2):162.

13. Machleder DJ, Banik R, Rosenberg RB, Parikh SR. An unusual case of rhabdomyosarcoma presenting as orbital apex syndrome. Int J Pediatr Otorhinolaryngol. 2005 Feb;69(2):249-54.

14. Dasgupta R, Rodeberg DA. Update on rhabdomyosarcoma. Semin Pediatr Surg. 2012 Feb;21(1):68-78.

15. Parham DM. Pathologic Classification of Rhabdomyosarcomas and Correlations with Molecular Studies. Mod Pathol. 2001 May;14(5):506-14.

16. Crist W, Gehan EA, Ragab AH, Dickman PS, Donaldson SS, Fryer C, et al. The Third Intergroup Rhabdomyosarcoma Study. J Clin Oncol. 1995 Mar;13(3):610-30.

17. El Sanharawi A, Coulibaly B, Bessede J-P, Aubry K. Paranasal sinus rhabdomyosarcoma: A rare tumor of poor prognosis. Eur Ann Otorhinolaryngol Head Neck Dis. 2013 Feb;130(1):26-9. 